\title{
Influence of Different Heat Input on Submerged Arc Welded Joints of High Strength Low Alloy Steel SX780CF
}

\author{
Houyi $\mathrm{Li}^{1}$, Xiansheng $\mathrm{Hu}^{1}$, Zhixiang Peng ${ }^{2}$, Youlong Zhou ${ }^{1,}$ * \\ ${ }^{1}$ School of Materials Science and Engineering, Southwest Jiaotong University, Chengdu, China \\ ${ }^{2}$ Chengdu Alang Science and Technology Co., Ltd., Chengdu, China
}

\section{Email address:}

lihouyi@my.swjtu.edu.cn (Houyi Li),869479578@qq.com (Xiansheng Hu),441244458@qq.com (Zhixiang Peng), zhouyoulong@swjtu.edu.cn (Youlong Zhou)

${ }^{*}$ Corresponding author

\section{To cite this article:}

Houyi Li, Xiansheng Hu, Zhixiang Peng, Youlong Zhou. Influence of Different Heat Input on Submerged Arc Welded Joints of High Strength Low Alloy Steel SX780CF. International Journal of Mechanical Engineering and Applications. Vol. 7, No. 4, 2019, pp. 101-105. doi: 10.11648/j.ijmea.20190704.12

Received: July 14, 2019; Accepted: August 15, 2019; Published: September 3, 2019

\begin{abstract}
SX780CF is a new type domestic high strength low alloy (HSLA) steel with tensile strength of $800 \mathrm{MPa}$, which was used firstly for pressure pipes in the hydropower unit. In order to improve the efficiency, SX780CF is generally welded by submerged arc welding (SAW), and a kind of special intelligent welding machine for large-scale pressure steel pipe was adopted, which can realize intelligent mechanized grouping and automatic welding in tunnel. In this paper, two different levels of heat input were used to weld SX780CF. The weldability of two joints was analyzed, the mechanical properties of the joints were measured, and the hardness distribution of the joints was tested. Meanwhile, the microstructure was observed. The results show that the properties of these joints welded by two different levels of heat input could satisfy the demand of the GB 50766 -2012 standard. The mechanical properties of the weld joint with larger heat input were slightly higher than those with smaller heat input. The hardened tendency of SX780CF is small, however, the steel with the thickness of $60 \mathrm{~mm}$ needs to be preheated at more than $112^{\circ} \mathrm{C}$. Comprehensive comparison shows that the submerged arc welding method with larger heat input has better efficiency and cost advantage, and it is worthy of promotion in hydropower project.
\end{abstract}

Keywords: SX780CF, High Strength Low Alloy (HSLA) Steel, SAW, Heat Input, Welding Procedure

\section{Introduction}

At present, large hydropower pressure pipes are usually made of 16MnR, WDB620 and other $500 \sim 600 \mathrm{MPa}$ grade steels [1]. The pressure pipeline used in large hydropower stations must have strong pressure carrying capacity, while the low carbon quenched and tempered steel has high tensile strength and yield strength, which can ensure the pressure bearing capacity and effectively reduce the thickness of the pressure steel pipe. The high strength low alloy (HSLA) steel with tensile strength of $800 \mathrm{MPa}$ obtains higher strength by special controlled rolling and cooling process and heat treatment process, which is the preferred material for pressure pipes [2]. However, the HSLA steel is sensitive to heat input during the welding process, and it is necessary to strictly control the heat input to ensure the quality of the weld joint. Using small heat input welding under preheating conditions, the joint performance is excellent, but the production cost is high in the project, the production efficiency is very low, and the installation and manufacture of large quantities is difficult. As a domestically produced the HSLA steel, SX780CF was first used in the production of large-scale pressure steel pipes at Wudongde Hydropower Station. Submerged arc welding (SAW) is a high-efficiency, low-cost welding method commonly used in the welding of water and voltage steel pipes. Therefore, studying the SAW process of SX780CF steel and selecting the appropriate heat input is the key to ensure the welding quality of the pressure pipe of Wudongde Hydropower Station, and it also has great significance for promoting the application of the domestic HSLA steel with tensile strength of $800 \mathrm{MPa}$. 


\section{Welding Method and Equipment}

The traditional technical process requires the manufacture of large-diameter steel pipes in the construction plant outside the tunnel, planning special roads for transportation, which result in a high initial investment [3]. In Wudongde Hydropower Station, a kind of special intelligent welding machine for large-scale pressure steel pipe was adopted, which can realize intelligent mechanized grouping and automatic welding in tunnel. And it also can effectively reduce input cost and improve the efficiency. The steel pipes with a diameter of $9 \sim 13.5$ meters can be welded by the special intelligent welding machine. The equipment schematic is shown in Figure 1.

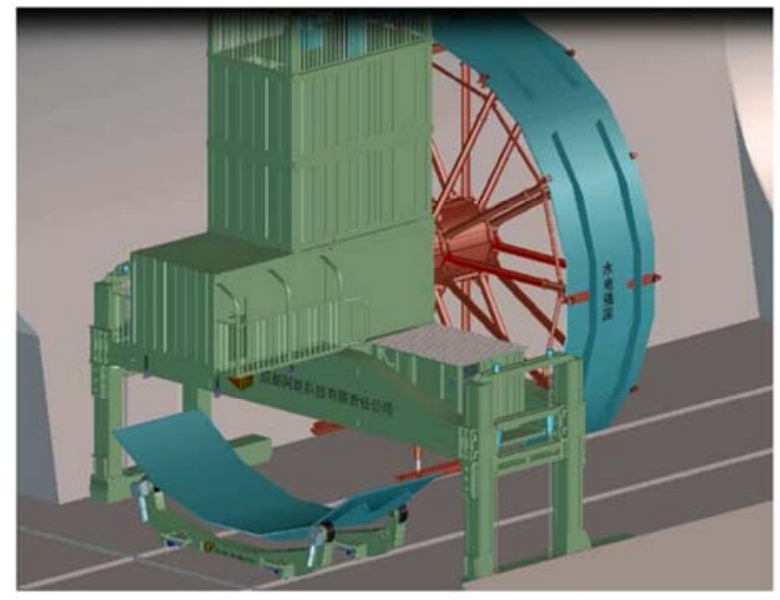

Figure 1. The special intelligent welding machine of large-scale pressure steel pipe.

In the construction process of Wudongde Hydropower Station, the multi-functional rolling welding trolley is used to transport steel pipes. The trolley can be used in combination with two sets.

It has 4 rollers that can be remotely controlled, which can adjust the 3 degrees of freedom during the pairing and welding process. It can also be used for transporting large diameter pipes in tunnels. The multi-function rolling welding trolley can adapt to the diameter of steel pipe of 9 13.5 meters. The equipment schematic is shown in Figure 2.

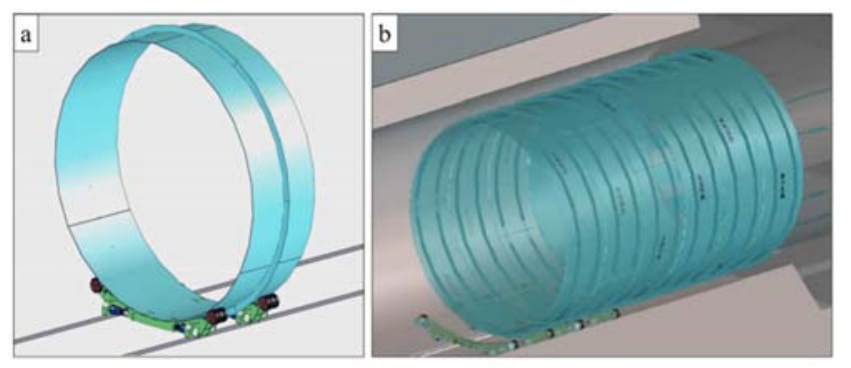

Figure 2. The multi-function rolling welding trolley (a) single-section pipe transport, (b) multi-section pipe transport.

\section{Material and Experimental Procedure}

The material that used for welding is SX780CF steel plate with a thickness of $60 \mathrm{~mm}$. The mechanical properties and chemical composition of the SX780CF steel are shown in Table 1 and Table 2 respectively. Yield strength is the specified non-proportional extension strength $0.2 \%$.

Due to the strict control of sulfur and phosphor in the SX780CF steel, the tendency of welding hot cracks is small, but attention should be paid to the problems of cold crack and embrittlement. The proper welding heat cycle should be ensured in order to prevent embrittlement during welding.

The CCT curve of $800 \mathrm{MPa}$ HSLA steel is shown in figure 3 [4]. The cooling rate in the shadow range could ensure that the heat-affected zone (HAZ) has sufficient plasticity and none of cold cracks.

Table 1. The mechanical properties of the SX780CF steel.

\begin{tabular}{ll}
\hline Property & Value \\
\hline Yield strength $(\mathrm{MPa})$ & 782 \\
Tensile strength $(\mathrm{MPa})$ & 819 \\
Elongation $(\%)$ & 18 \\
$-40^{\circ} \mathrm{C}$ Impact energy $(\mathrm{J})$ & 249 \\
\hline
\end{tabular}

Table 2. The chemical composition of the SX780CF steel.

\begin{tabular}{ll}
\hline Element & wt. (\%) \\
\hline Carbon (C) & 0.09 \\
Silicon (Si) & 0.25 \\
Manganese (Mn) & 1.20 \\
Phosphor (P) & 0.009 \\
Sulfur (S) & 0.002 \\
Chromium (Cr) & 0.47 \\
Nickel (Ni) & 0.53 \\
Molybdenum (Mo) & 0.45 \\
Vanadium (V) & 0.039 \\
Copper (Cu) & 0.21 \\
Boron (B) & 0.003 \\
\hline
\end{tabular}

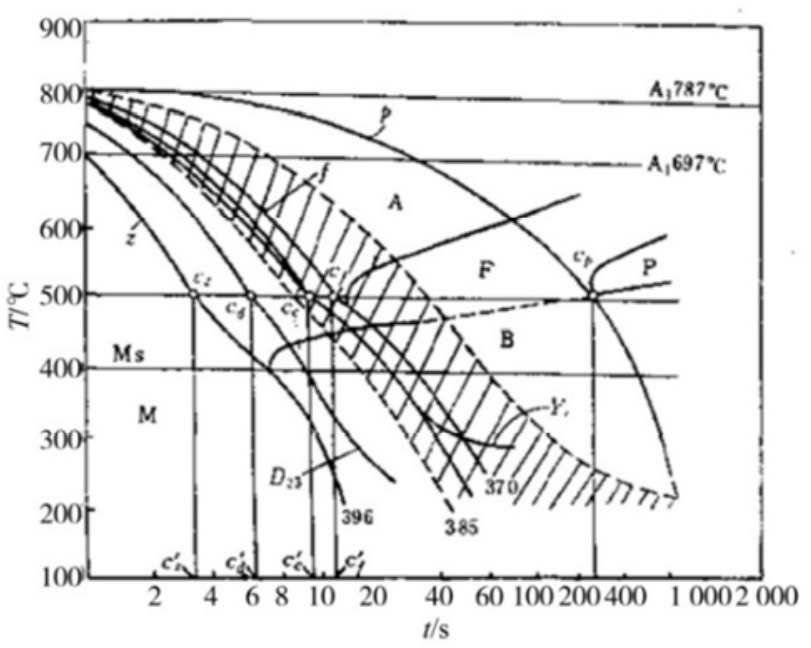

Figure 3. CCT curve of 800MPa HSLA steel.

However, when thicker steel plates are welded with larger wire energy, the cooling rate will still exceed the upper limit. It is necessary to preheat the base metal before welding. The preheating temperature of SX780CF steel can be calculated according to formulas 1-3 [5,6]. The calculation results are shown in Table 3. 


$$
\begin{gathered}
C e q=C+\frac{S i}{24}+\frac{M n}{6}+\frac{N i}{40}+\frac{C r}{5}+\frac{M o}{4}+\frac{V}{14} \\
P_{c}=C+\frac{S i}{30}+\frac{M n}{20}+\frac{C u}{20}+\frac{N i}{60}+\frac{C r}{20}+\frac{M o}{15}+\frac{V}{10}+5 B+\frac{\delta}{600}+\frac{H}{60} \\
T_{0}=1440 P_{c} \times 100-392
\end{gathered}
$$

Where $C_{e q}$ is the carbon equivalent, $P_{c}$ is the sensitivity coefficient of cold crack, $T_{0}$ is the preheating temperature, and $\delta$ is the thickness of the base metal.

Table 3. Preheating temperature parameter calculation result.

\begin{tabular}{ll}
\hline Parameter & Calculation result \\
\hline$C_{e q}$ & $0.52 \%$ \\
$P_{c}$ & $0.35 \%$ \\
$T_{0}$ & $112^{\circ} \mathrm{C}$ \\
\hline
\end{tabular}

According to the calculation results, there is a tendency of cold cracking of the SX780CF steel during the welding process. Therefore, the base metal needs to be preheated to above $112^{\circ} \mathrm{C}$ before welding.

SAW of SX780CF steel plate was carried out using two kinds of heat input. The sample number with a heat input of $30 \sim 40 \mathrm{KJ} / \mathrm{cm}$ was $1 \#$, and the sample number with a heat input of $20 \sim 25 \mathrm{KJ} / \mathrm{cm}$ was $2 \#$. The welded joint adopted an asymmetric $\mathrm{X}$-shaped groove, the welding material was CHW-80CF and CHF606. The weld bead of the welded joint is as shown in figure 4.

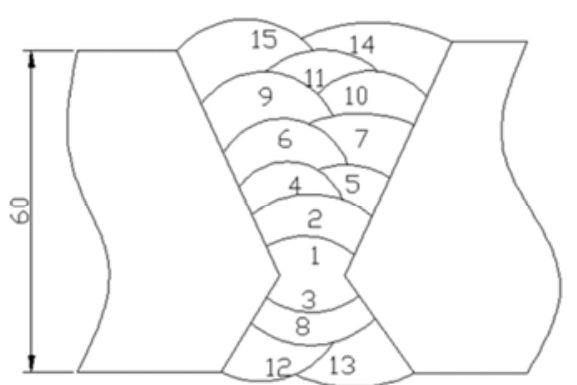

Figure 4. The weld bead of the welded joint.

\section{Experimental Results}

\subsection{Mechanical Properties of Welded Joints}

The mechanical properties of the welded joint specimens were tested. The experimental results were evaluated according to the national standard GB 50766-2012 Code for manufacture installation and acceptance of steel penstocks in hydroelectric and hydraulic engineering [7], and the mechanical properties of the welded joints met the standard requirements. The experimental results are shown in table 4 . The $-40^{\circ} \mathrm{C}$ impact energy of welding metal and $\mathrm{HAZ}$ was much higher than the standard requirement of $47 \mathrm{~J}$. It could be explained that the welded joint has good crack resistance and

\begin{tabular}{|c|c|c|c|c|c|}
\hline \multirow{2}{*}{ Sample } & \multirow{2}{*}{ Tensile strength (MPa) } & \multirow{2}{*}{ Break position } & \multirow{2}{*}{$180^{\circ}$ bending experiment } & \multicolumn{2}{|c|}{$-40^{\circ} \mathrm{C}$ Impact energy $(\mathrm{J})$} \\
\hline & & & & Weld metal & HAZ \\
\hline $1 \#$ & 831 & Base metal & None of crack & 88 & 152 \\
\hline $2 \#$ & 817 & Base metal & None of crack & 69 & 234 \\
\hline
\end{tabular}
crack arrest resistance [8].

Table 4. Results of mechanical properties.

\subsection{Inhomogeneity of Welded-joints}

The hardness can reflect the inhomogeneity of the properties of welded-joints. The hardness curves of the two-group samples of the top bead of welded joints are shown in Figure 5. The hardness of the HAZ of the two-group samples was less than that of the base metal, indicating that there is softening in the HAZ.

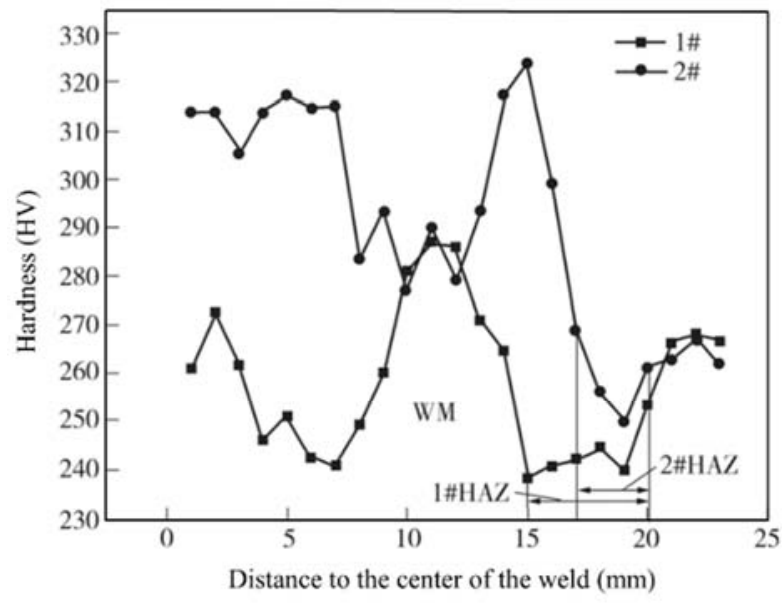

Figure 5. The hardness curves of the top bead of welded joints.

\subsection{Metallurgical Structure of Welded Joints}

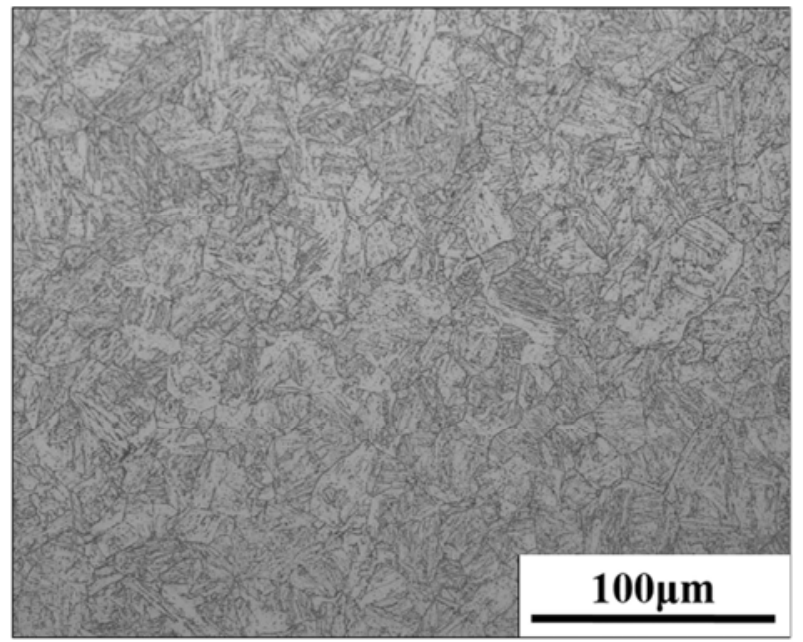

Figure 6. The metallographic structure of the base metal.

Figure 6 shows the metallographic structure of the base metal, and figure 7 shows the metallographic structure of the welded joints of the $1 \#$ and $2 \#$ sample. Inside the weld of the $1 \#$ sample, the metallographic structure is bainite, and $2 \#$ is bainite and a small amount of pro-eutectoid ferrite. The 
SX780CF steel is bainite steel, so the metallographic structure of the HAZ and base metal are bainite. However, the grain size is obviously different in the HAZ. The gain close to the weld is larger than that close to the base metal. For welded joints with different line energy, there is no obvious difference in metallographic structure in the same area.
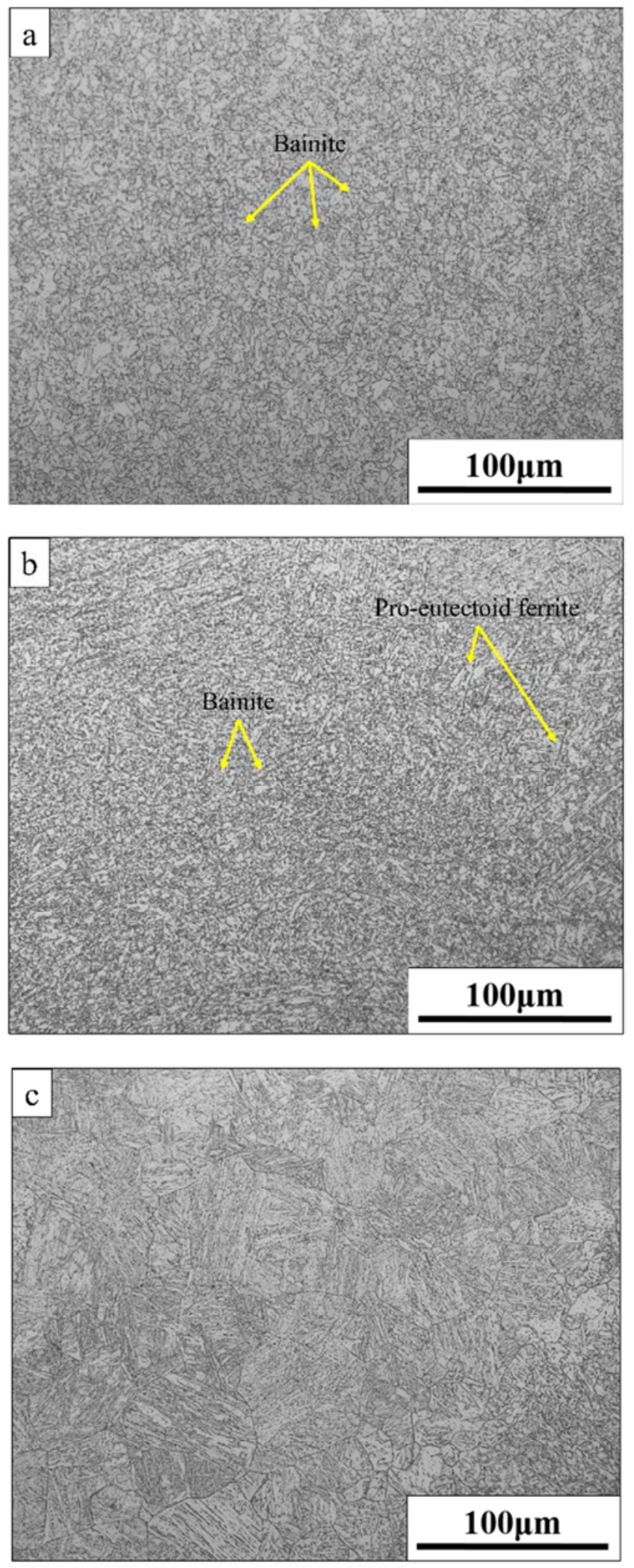
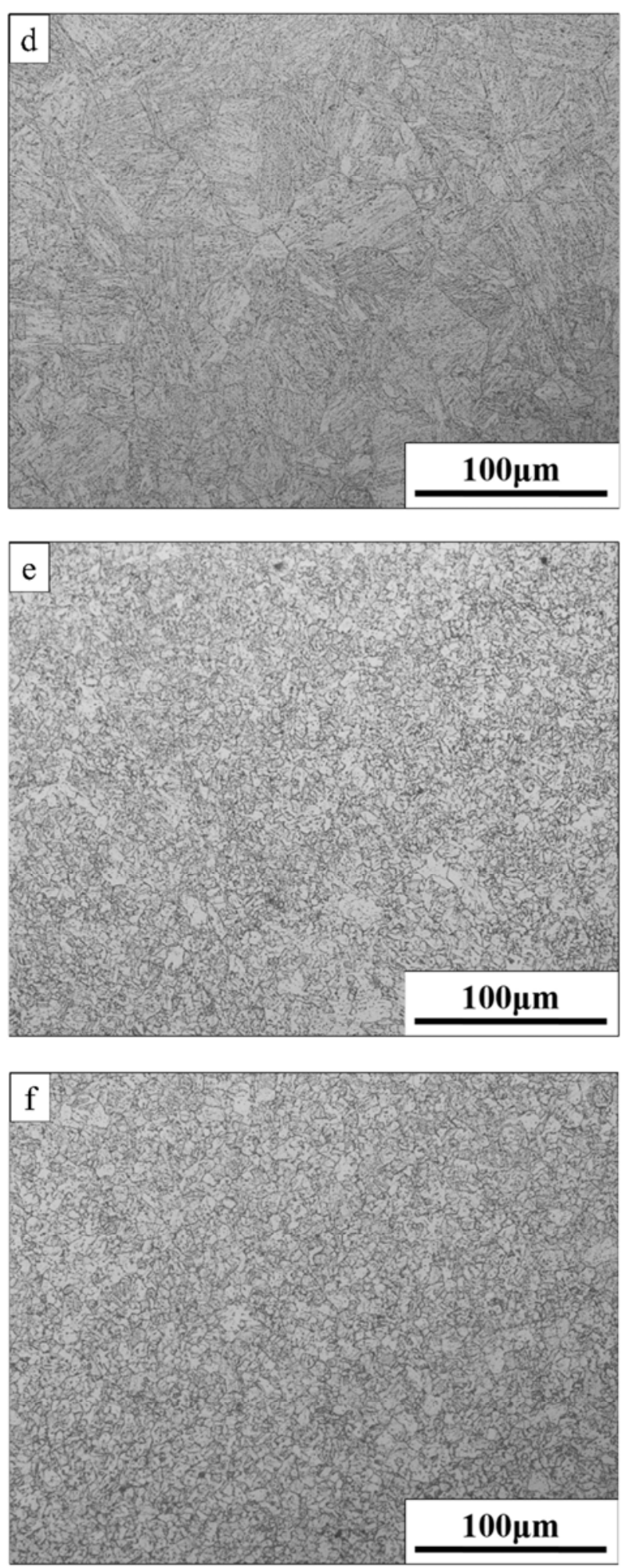

Figure 7. The metallographic structure of the welded joints of the $1 \#$ and $2 \#$ sample, (a) weld metal of $1 \#$ sample, (b) weld metal of $2 \#$ sample, (c) coarse grained region of $1 \#$ sample, (d) coarse grained region of $2 \#$ sample, (e) fine grained region of $1 \#$ sample, and (f) fine grained region of $2 \#$ sample.

\section{Discussion}

HSLA steel cannot obtain higher strength only by adding alloy and normalizing. Generally, high strength steel with 
tensile strength greater than $490 \mathrm{MPa}$ will undergo quenching and tempering treatment. Softening of HAZ is a common problem in welding tempered steel. When the temperature of heat-affected zone reaches the tempering temperature of base material to Ac1, softening phenomenon will occur [5]. At the same time, the special controlled rolling and cooling process could make the grain of the SX780CF steel finer. However, the growth rate and growth driving force of the grain are inversely proportional to the grain diameter [9]. Therefore, the grain of the SX780CF steel has a certain tendency to grow during the welding process.

Since the heat input of the $1 \#$ weld was larger during the welding process, the range of the HAZ was wider, which was more affected by the welding heat cycle, the peak temperature was higher, and the austenite grain was coarser at high temperature. The solubility of carbide decreased and then precipitated [10], and the grain growth was more obvious. Therefore, the impact energy of the HAZ of 1 \# welded joint is lower than 2\# welded joint, and the hardness is also the same. Combined with the CCT curve, the lower the cooling speed of welded joints, the higher the content of the first-formed ferrite in the HAZ, and the lower the hardness of the heat-affected zone.

\section{Conclusion}

Effects of SAW process with different heat input on the welded joints of SX780CF steel was investigated in the present work. The main conclusions can be summarized as follows:

1. The mechanical properties of welded joints with heat input of $30 \sim 40 \mathrm{KJ} / \mathrm{cm}$ and $20 \sim 25 \mathrm{KJ} / \mathrm{cm}$ meet the requirements of the GB 50766.

2. SX780CF steel has a certain tendency of hardening during welding, so the preheating temperature should be higher than $112^{\circ} \mathrm{C}$ when the steel plate thickness is 60 $\mathrm{mm}$.

3. Larger heat input of $35 \sim 40 \mathrm{~kJ} / \mathrm{cm}$ is adopted for welding, which is more efficient and can reduce production cost while guaranteeing mechanical properties of welded joints.

\section{References}

[1] Z. L. Tang, S. P. Xu, S. Peng, Z. B. Li, Z. J. Zhang, J. Y. Huang, "Research and Development of Q690CFE Steel Plate for Pressure Steel Pipe and Spiral Case of Hydropower Station," Steel Rolling, vol. 35, pp. 79-80, 2018.

[2] Y. Zhai, Z. T. Li, X. Zhang, H. Liu, "Development of 800MPa Hydropower Steel Pipe for Large Heat Input," Welding Technology, vol. 45, pp. 66-69, 2016.

[3] L. M. Duan, Y. Xu, "Application of New Technology on Super Large Penstock Manufacture in Liyuan Hydropower Station," Water Power, vol. 41, pp. 88-90, 2015.

[4] I. Michio, "Welding Processing," Seibundo-Shinkosha Co., Ltd., Tokyo, 1971.

[5] Z. F. Zhou, "Welding Metallurgy," Southwest Jiaotong University Press, Chengdu, 2012.

[6] R. H. Espy, "Weldability of Nitrogen-Strengthened Stainless Steels," Welding Journal, vol. 61, pp. 149-156, 1982.

[7] The standard of People's Republic of China. GB/T 50766-2012 Code for manufacture installation and acceptance of steel penstocks in hydroelectric and hydraulic engineering, 2007.

[8] Z. C. Liu, Z. Sun, W. Guo, X. J. Li, Y. Wu, "Development of Steel Plates for Large Scale 780MPa Hydropower Stations with Excellent Low Temperature Toughness and Weldability," 8th National academic conference on pressure pipeline of hydropower station, Chengdu, China, 2014.

[9] C. H. Xu, "Controlling on Microstructure and Performances of Welding Joints of $800 \mathrm{MPa}$ Ultra-Fine Grained Steel," Master's Thesis, Harbin Institute of Technology, Harbin, 2009.

[10] Y. J. Li, "Welding of High Strength Steel," Metallurgical Industry Press Co., Ltd., Beijing, 2010. 